\title{
Traditional Housing in Sustainable Architecture
}

\author{
Mazdak Irani, PhD Candidate \\ University of Sydney, Sydney, Australia \\ Email:mazdakirani@mail.com
}

\section{Doi:10.5901/mjss.2014.v5n8p666}

\begin{abstract}
In traditional housing architecture has always been tried to provide safe place to live and create appropriate positions with coordinate to its environment. In fact, the status directly affected by geography and climate conditions. In Iran, four different climates such as hot and humid, hot and dry, mild, and humid and cold caused to establish various architectures (especially in the design of traditional housing) in coordinate with climates. Such these places built by applying traditional materials which have less effect on environment and also reduce amount of energy caused to increase the environmental sustainability and rise durability of buildings. Hence, in this article tried to study about the traditional housing architecture according to environmental sustainability and use of economical traditional housing and then estimate their most important samples.
\end{abstract}

Keywords: sustainable architecture, traditional architecture, local architecture, traditional housing

\section{Introduction}

According to increase significant global warming and its results beside expensive and limited fossil fuels, climate designing and adjusted energy consumption in buildings and use more environmental nature resources are important significantly ( Givoni:1977,23). In this regard, adjusted architecture with climate is appropriate solution to provide more comfort status that lead to use mechanical heating and cooling equipments and energy consumption and finally reduce pollutions. The subject of climate designing to minimize the consumption of fossil fuels is approved by global Meteorological Organization.In another report by this organization, the relation between gas condition and consumption in buildings will be studied as well as reduced fuel consumption by applying climate potentials (Amiri, 2002:8). There are also many researches have been done to estimate the relationship between climate and human comfort and some climate factors used to evaluate comfort status by some temperature and energy and physiological balance charts (Olgay, 1975:185), (Govini, 1997:96), (Kasmaie, 2004: 20) (Mieczkowski, 1985:23) or models (Matzarakis, 2001: 102), (Sabnolo, J. and de Dear, R. A. 2003:725).In this regard, Olgay (1975) first suggested a chart and presented the role of atmospheric phenomena for human comfort. Olgay in his bioclimatic table also showed that temperature and mild because of their direct impact on human comfort are the most important factors (Razjoyan, 1998: 45). Givoni showed the comfort area and different bioclimatic status in relevance to both relative temperature and humidity factors and used the mean maximum temperature and minimum relative humidity to determine bioclimatic status and building requirements (Kasmaie, 1993: 166).Kaviani also evaluated bioclimatic status and provided bioclimatic maps for country by different methods (Kaviani, 1995:127).He, according to another research, estimated the role of wind and its energy potential in different areas of country (Kaviani, 1995:127). Esmaeli and et,al. (2010:125) used predict mean vote (PMV) index and thermal stress (STT) as well as Zolfaghari (2008:142) showed comfort climate application in tourism industry for respectively both cities; Chabahar and Tabriz.But the application of such assessments in relation to building construction and architecture in harmony with the climate status can be found in many researches.Alijani studied the role of climate to building construction and explained various methods of building based onangle of solar radiation (Alijani,1994,45). Jahanbakhsh studied about thermal requirements in Tabriz and estimated the effect of heating and cooling degrees on lifestyle (jahanbakhsh,1998,67).Papli evaluated the effect of hot and dry climate on Turkoman traditional housing (Papli, hot and dry, 1992,15).Lashkari studied about the orientation optimization of Ardabil free spaces and suggested some ways for optimal construction of buildings and passages (Lashkari,2003,19).Amiri evaluated thermal comfort in indoors environment and housipng design practices of Qom (Amiri, 2004, 55).Saligheh studied the modeling of housing consistent with climate in Chabahar and focused on use of wind and solar energy optimality to improve thermal conditions and thermal and comfort indexes (Saligheh, 2004,146).Tavoosi and et,al. estimated the type of climate and establishment of windows, canopy and green spaces for architecture of new schools in Isfahan(Tavoosi, 2008,97). Additionally, in this 
article tried to use climate indexes to evaluatedaily climate assessment scale and thenharmony of Iran traditional architecture and four climate based on effective parameters (wind,angle of solar radiation and its position) will be studied.

\section{Iran Traditional Housing and Sustainable Architecture}

According to four general climate in Iran, traditional architecture of hot and humid area, hot and dry area, moderate area and humid and cold area will be evaluated for constructions based on climate and sustainability status. Because housing or building topology in different areas are affected by climatic and even cultural environmental factors.

\subsection{Architecture of moderate and humid area}

It is the most rainy area located in north of Iran with high humidity and heat in summer. Hence, main factor to form architecture in Iran is due to continuous rain and high humidity.

The building spatial structure: formation of local architecture is based on modulated square and is developed linearly along the East - West and perpendicular to the wind flow. This formation is known as extroverted architecture can obvious in local architecture with direct physical and visual connection to outdoor spaces without courtyard and height extension.

Effect of air flow and sunlight on building: sloping roofs are located in one or two side(s) of building close to the floor in the direction wind flow and are as a barrier against the infiltration of rainwater into the building by the wind flow. " Additionally, they are located also higher than ground surface in order to prevent infiltration of humidity into building and air flow in the space between the ground and floor causes to humidity evaporates and air conditioner as well as dry and usable the floor.

The buildings with two or three floors are located on a side of yard with underground service spaces or in the side of yard are known as a head pattern. (1).

Fig. 1: Plan of one Head design

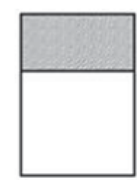

\subsection{Architecture of hot and dry area}

It refers to many central plateau towns in Iran because of its buildings' introverted architecture has been constructed compatible with climate status. The features of this area include dry, low water and high temperatures summer and sometimes sand storms and wind flow in different directions and also too cold winter in year.

The building spatial structure: introverted structure is main factor for local architecture of hot and dry areas. This architecture includes central yard and the rooms usually are located in the four directions and vent constructed for indoor air conditioner in the corner of the building. Yards usually are constructed in shape of sunken garden (sometimes flat). In fact, rooms in sunken garden are located on underground around it and lead to cool spaces for the underground rooms as well as proper use of air flow, hence there is no need for artificial cooling devices and therefore, energy consumption will be reduced.

Effect of air flow and sunlight: warm and dry climate need to more compatible with nature and environmental circumstances because their summer always include heavy storms with sand and high temperature in summer and too cold in winter. For example, compacted plan form requires for this climate (hot and dry) to locate less levels against sunlight. As mentioned, the buildings because of intense sunlight radiation in summer and too cold in winter are located on the south and southeast to get a lot of energy in winter. These building are located as two parallel heads in north and south directions (figure 2).

Fig. 2: The plan of two parallel heads

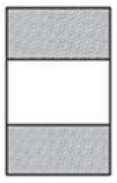




\subsection{Architecture of hot and humid area}

It refers to south coastal area of Iran involve both inside and extroverted architectures is known as a link of two type of architecture for inside-oriented architecture for hot and dry area and extroverted architecture for moderate and humid area.

Generally, very hot summer and high humidity in all seasons are climate characteristics in this area as well as low temperature differences between day and night.

The building spatial structure: as mentioned local architecture adjusted with this climate is a mixture of introverted and extroverted. Therefore, addition to roofed porches, for flowing internal air in rooms, some windows are located against each other in south and north directions.

Effect of air flow and sunlight: appropriate use of air flow is main role to improve the difficult conditions of climate. Hence, the buildings are located to the sea and wind direction to use any breeze flow. In order to air flow, internal and external windows are always located against each other for air flow. Also, in order to transfer the wind flow (breeze) from the sea to internal spaces, one or four-sided vent (only to the south) are used. The buildings are constructed in the form of three U-shaped heads and in three sides of courtyard. (figure 3 ).

Fig. 3: The plan of three U-shaped heads

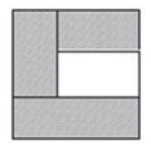

\subsection{Architecture of cold area}

This architecture is shaped like the introverted architecture of hot and dry area but with differences are required for cold weather. The climate in this area is very cold in winter and hot and dry in summer. According to this climate, the buildings should be constructed so that able to absorb maximum heat in winter and minimum amount of heat in summer.

The building spatial structure: the buildings are located in north and south directions. The windows are constructed double means a window open into the room and another open out.

Effect of air flow and sunlight : as mentioned, the buildings are constructed to use maximum heat in winter and minimum heat in summer significantly. Hence, there are located tall walls and main doors and the windowsare made doubleglazed to keep temperature in winter. The buildings are not required to air flow because of high cold weather. But, large windows are built to transfer more light into the building. These buildings are constructed in the form of two Lshaped heads and perpendicular to each other in north and south directions. Totally, full and empty spaces are formed to minimize heat exchange with outside through establishing a dense texture (figure 4).

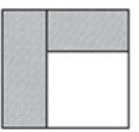

Fig. 4: the plan of two L-shaped heads

\section{Arrangement and Building Structure of Traditional Housing in Traditional Cold Areas of Iran}

Using data from weather stations and available methods to impact climate status on buildings formation, thermal requirements of the building are as follows:

- about $85.5 \%$ in cold seasons of year

- $\quad$ about $3.19 \%$ in hot seasons of year

- about $11.7 \%$ in comfort status

According to these thermal requirements, there are some main purposes to design urban settlements as mentioned below.

- avoid energy dissipation rate

- $\quad$ provide maximum solar energy in cold seasons of year

- avoid infiltration of cold wind flow in cold seasons

- avoid infiltration of sunlight into building in heat seasons of year 
Use of solar energy to space heating in cold seasons is required in sustainable design of traditional architecture in Iran, so main part of building should be located in west-east. Of course, designing the building plan in relation to daily activities in accordance with the sun direction is possible to use space heating by solar energy. In cold seasons the sun moves from southeast to northwest and it is better to locate main rooms and doors of buildings in south direction (inactive use of solar energy ) and also solar boxes must be created near the building. These boxes are able to heat around the house and addition to use external spaces of building for long-time, also it will help to create warmer environment as well as reduce waste of heat. Side walls and greenhouses are appropriate for that. The context of buildings is related to locate and connect various residential buildings in a place. The context of building in this area should be compact and dense for minimal waste of temperature and maximum stability of structure in cold season of year. The compact and connect of various buildings to each other can lead to reduce the area of external surfaces and increase thermal capacity or final delay time of these series and therefore, the effect of climate status is less for each units. Hence, it is better to create compact and dense context for traditional cities of Iran through constructing common walls betweenneighboringunits and planning of the buildings. With the common walls, addition to the buildings' external surface, heat dissipation also will be reduced.Although, it is not essential in climate status to provide air flow in building's interior spaces and its surrounding of traditional architecture, the minimum distance between consecutive buildings is a function and shadow behind the building is in the sun direction. In other hand, the distance between buildings should be enough to provide solar heating for interior spaces in cold seasons. One of the purposes of sustainable design in architecture is to use solar energy for indoor heating. So,if the slope of the land is to the south,it is possible to estimate the minimum distance by shadow on the ground floor in cold seasons but it is difficult if the slop of land is to the north. Of course, in building sets, it is possible to decrease shadow through locating smaller buildings in south direction. This architecture is design for traditional houses in cold areas (Figures 5,6,7 and 8, Sadr; 1992)

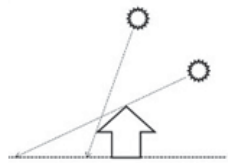

Fig. 5: Minimum and maximum shade in summer and winter noon

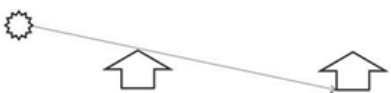

Fig. 6: Calculating the minimum distance to avoid shadows on buildings

Fig. 7: For slopes in the sun direction
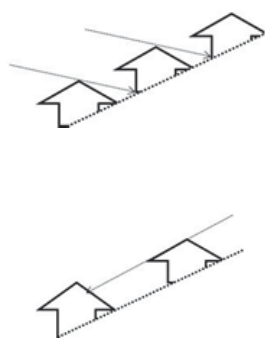

Fig. 8: For slopes behind the sun- provide solar heating through roof

\section{Vents as natural cooler for traditional housing of hot areas}

Vent is as a cooling system to provide air conditioning through wind renewable energy. It can be observed in traditional architecture of hot climate in Iran.Vent is part of the buildings constructed in hot and dry or hot and humid areas in Iran, it has significant role to provide comfort status through wind flow and use of pure nature energy for temperature adjustment and coordinating the residential space temperature. Vents consist of several components and some of them are for aestheticisms' aspects and some others are heavily involved in the vent performance. These factors can help to know significantly about vents structure.Understanding these components will significantly contribute to a better understanding of the vent structures. Followings are main components of a vent.

Shelves:it locates on top of the vent as a channel to pass airflow.

Stem:it locates as a part of vent between shelves and roof. 
Blade: it consists of clay and bricks.

Main blade:it consists the walls that extend to the center of tower and divide the ventchannel into smaller ones.

Sub blade:it consists the walls that never extend to the center of tower but towidth of the external walls. Sub blade is visible aswing air conditioner in the vents.

Open and closed gates: gate is a space between two blades (both main and sub blades). If air can flow among this space, it is open gate and otherwise, it is closed gate (figure 9, Mahmmodi, 2003).

Fig. 9: Type of common vents in section

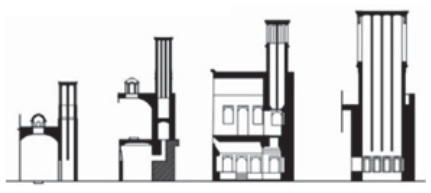

\section{Using Heating and Cooling of Colored Glasses in Traditional Housing}

Iran have first place for solar energy in all around the world. Solar radiation ratio in Iran is estimated between 220 to 1800 $\mathrm{Kwh} / \mathrm{m}$ in year. It is more that global average. Special coverage are used to reduce glass emission. When glass heated, it reflects the heat instead of emission. Most areas that require for high heating use low emission glasses. Because of low solar radiation in these areas, it is required to use solar radiation energy significantly and mechanical system should be used to avoid heat dissipation. In this regard, low emission coverage can help to avoid heat dissipationby emitted long wavelengths to outside. It has important role for indoor heat protection. These glasses can be used and protected heat into building in hot areas and lead to serious problems for residents' heating comfort. Beside, long wavelength emission into building ( by heated colored glasses through absorb radiation) lead to avoid their positive effect in direct radiation energy. Therefore, some approaches can be used to prevent these waves entering into the building significantly. Although, in Iran about two thirds of areas have cold climate and it is not possible to use suggests and methods of cold areas, practical approaches seem are essential to avoid indoor heating extremely. In this regard, colored glasses are used significantly for low emission sets in traditional architecture of Iran (figure 10).

Fig. 10: A type of colored glasses in traditional architecture of Iran

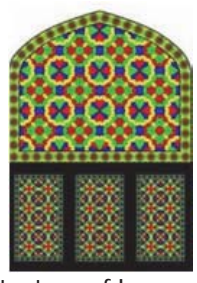

\section{Shovadans of Heating System for Hot and Dry Areas of Traditional Housing in Iran Traditional Architecture}

Shovadan is a space that dig about 5 to 12 meter below the old buildings and available through several stairs. According to geotechnical characteristics of the soil in these areas architects are not required to structural elements for shovadans' construction and their walls almost covered by stucco. Some of the shovadans are without decoration elements. Many shovadans are linked each other by underground tubes cause a local relationship in underground as well as access to several old housing. These complex set will be linked to river through shovadans of neighboring houses to river to use its coolness. Most shovadans are used in hot summer days. So, there is another lifestyle below the city into shovadans (figure 11, Mahdi, 1998).

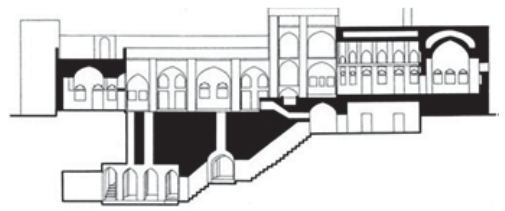

Fig. 11: A type of internal architecture of Shovadan 


\section{Conclusion}

In this research tried to study the characteristics of traditional housing in Iran traditional architecture by four climates as moderate and humid, hot and dry, hot and humid and cold to show the relationship between old (ancients) architecture in environmental sustainability. In local buildings, all builders has been used renewable energy such as air flow, sunlight and etc, for construction buildings, they also tried to reduce negative impact on environment. Most important point in new architecture is related to more use of non-renewable energies (fossil) because of inappropriate materials and their transformation and also false design of building through applying heater and cooler advices based on climate status. Hence, appropriate use of local materials and combine them with the new construction status and through applying the specialists' efficient practices in energy can access significantly to renewable energies such as solar and wind energies for buildings' heating- cooling and ventilation. The cooperation between architects and specialists is important to use new technologies and create new architecture in consistent with climate status for each area.

\section{References}

Amiri, A. (2001), "Impact of climate on Qom architecture". thesis for M.A. in Climatology and Hydrology, Ray Azad University.

Alijani, B. (1994), " New Attitude to use Climatology for R \& D Management, Journal of Geographical Researches, NO. 35.

Esmaeli, R. (2007)," Study of delayed frosts of spring from point of statistic-synoptic views and its effects on Gardening products", thesis for M.A in Climatology in environmental planning, Sistan and Baluchestan Uni."Faculty of Geography and environmental planning.

Esmaeli, R. Saber Haghighat, A, MAlboosi, Sh (2010), " Evaluate the comfort climate status in Chabahar to develop tourism", 4th International Conference of Islamic Worldgeographers, Zahedan.

Ghayor, H, (1993), " Application climate of temperature and radiation in relevance to architecture", Journal of Geography Education, NO.37.

Givoni B. (1997), "Estimation of the effects of climate on man:Development of a new thermal index, Report to Unesco building",Research Statistics: 85-136

Jahanbakhsh, S.(1998), " Study of Human bioclimatic in Tabriz and the buildings' heating requirements", Journals of Geographical Researches, NO 48.

Kasmae, M. (1990), " Climate and Architecture of Khouzestan-Khoramshahr", Centre of Researches and Urbanization, Dad publishing Co.

Kasmae, M, (2004), "Climate and Architecture", Centre of Housing Researches.

Kasmae, M, (2004), "Climate and Architecture", Khak publishing Co., Esfahan Uni.

Kovangiz, B, (1989), " Guide for Climatic design", Translated by MortezaKasmae, Centre of Housing Researches.

Lashkari,H. (2004), " Optimize free spaces direction in Ardabil based on Climate status", Journal of Geographical researches, NO. 79.

Matzarakis, A. (2001), "Climate and Bioclimatic Information for the Tourism in Greece", Proceedings of the 1st International Workshop on Climate, Tourism and Recreation", International Society of Biometeorology, Commission on Climate, Tourism and Recreation 101- 109.

Meteorology Organization (2007), " Statistical Annals of Synoptic Stations of TorbateHaydarieh, Kasmar and Gonabad and trenchant station of FeyzAbbad".

Mieczkowski, Z. (1985), "The tourism climate index: A method for evaluating world climates for tourism", The Canadian Geographer 29: 220-23.

NajarSaligheh, M, (2005), "Architecture in consists with climate (case study of Chabahar)", Journal of Geography and Development, Sistan and Baluchestan Uni. NO. 4, Winter.

Olgay, V. (1973), "Design with Climate", Princeton University Press, p. 185.

Papli, hot and dry, M, Vosoughi, F, LabafKhaniki, M (2000), " Turkamen Housing, practical analysis of a technical and social evolution", Journals of Geographical Researches, NO, 58 \& 59 .

Ramezani, B. (2006), " Identify bioclimatic comfort areas in Gilan shores", Geographical Journal of country, Islamic Azad University.

Razjooyan,M. (1988), " Comfort by adjusted architecture with climate", ShahidBeheshti Uni.

Sabnolo, J. and de Dear, R. A. (2003), "Field study of thermal comfort in outdoor and semi-outdoor environments in subtropical Sydney Australia", Building and Environment 38: 721-738.

Safaee, mohammadmahdi, "shavadan; the sustainable architecture in the city of dezful in iran",1998

Tavoosi, T. (2008), " architecture climate of new schools in Esfahan", Journal of Geography \& development, Sistan\&Bakuchestan University, NO. 11, Spring and Summer.

Zolfaghari, H. (2007), " Provide the appropriate schedule for Tourism in Tabriz by PET and PMV", Geographical Researches, NO, 62, pp, 129-141. 